\title{
Corporate Social Responsibility and Financial Performance in Hospitality Industry: A Critical Review
}

\author{
C. Lyu ${ }^{1}$, M. Wang ${ }^{1 *}$, R. Zhang ${ }^{2}$ and Y. N. Ng ${ }^{3}$ \\ ${ }^{1}$ School of Business, Macau University of Science and Technology, Macao 999078, China \\ ${ }^{2}$ Faculty of Business Administration, University of Macau, Macao 999078, China \\ ${ }^{3}$ School of Hospitality Management, Macao Institute for Tourism Studies, Macao 999078, China \\ *Corresponding author. Email: wangmingchang@hotmail.com
}

\begin{abstract}
This paper aims to investigate the status quo of the research in relation to corporate social responsibility (CSR) and financial performance in hospitality industry. A critical review has been conducted based on 69 good quality journal papers by using both quantitative and qualitative content analysis methods. The results show quantitative method is the main stream of methodology used and US dataset is more preferable. Besides, stakeholder perspective represents the main school of thoughts in recent years. Although majority of the studies have proved positive association between CSR and financial performance, negative relationship is still evidenced by research with samples of loss-making firms. Furthermore, many studies suggest developing conceptual framework or furthering the extant theoretical framework to cope with the rapid changes in CSR fields as well as the diversified CSR behaviour of the public companies in today's business world. The findings of this critical review bring additional insight to the CSR and hospitality academia and can stimulate scholars' further study on how to achieve balance between social and financial performance of public companies in this industry. Theoretically, this critical review enlightens the need for developing/extending the classical theoretical model for matching with the new phenomenon in the CSR field. Practically, the review results also provide valuable information and suggestions to industry operators for their improvement in CSR practice.
\end{abstract}

Keywords: corporate social responsibility; financial performance; hospitality industry; stakeholder

\section{INTRODUCTION}

Facing to various global challenges such as energy consumption, financial crisis, natural disaster, the value of corporate social responsibility (CSR) in hospitality industry keeps rising [1]. Since 1990s, firms in this sector have gradually integrated CSR into their daily operations. This practice demonstrates industry operators' commitment to the sustainable development in tourism.

Although CSR has been widely discussed in the extant hospitality literature, very few studies investigated its impact on company's financial performance [2]. Instead, many scholars focus on the aspects of charity, labor issues, guest service, environmental protection and etc. However, according to the principle of financial management, the most basic social responsibility of a company is to fulfill their responsibility to shareholders which is to maximize shareholders' wealth [3]. In this regard, generating financial return is considered as a primary goal of conducting CSR. Otherwise, insufficient resources can be generated by the companies for delivering other CSR work, such as improving staff benefits, serving community and making investment in environmental friendly facilities. For this reason, the association between CSR and financial performance is an important research theme for hospitality industry. Thus, a critical review is emergently needed for understanding and analyzing the overall research directions, findings and status quo of the extant literature related to this field.

\section{LITERATURE REVIEW}

\subsection{Theoretical basis}

There are three famous theories in the academia to explain the motivation of enterprises to engage in social responsible behavior. They are political economy theory (PET), legitimacy theory (LT) and stakeholder theory (ST). PET has a long history. It emphasizes that society, politics and economy are inseparable. Therefore, economic problems cannot be separately discussed and analyzed from social and environmental issues [4]. As for LT, it was derived from PET. LT has been widely used in CSR research [5]. According to Lindblom [6], the applicable condition of legitimacy is that the value system of an entity is consistent with the larger social system to which the entity belongs. If there are differences between the two 
systems, it will threaten the legitimacy of the entity. The main focus of LT is to maintain the legal and social recognition of entities by meeting regulatory requirements [7]. In another words, in order to maintain legitimacy, entities must take socially desirable actions [8]. However, Parker [9] realized some limitations of LT, including obvious overlap with the theoretical concepts of PET, uncertainty in predicting management behavior and etc. The ST makes up for the shortcomings of the first two theories to some extent. As Freeman, wicks and Parmar [10] point out, corporate management can be regarded as a process of balancing a series of interests and connections among stakeholder groups. Freeman's [11] classic definition of stakeholders is any group or individual that can affect or be affected by the achievement of organizational goals. Among various stakeholders, shareholders are considered as one of the most important groups for companies to fulfill their social responsibility [12]. Thus, for this critical review, ST provides a more appropriate basis for exploring the extant research findings regarding the contribution of CSR on shareholders' interest.

\subsection{CSR and financial performance}

"How does social behavior lead to impacts on company's financial performance" has been a topic of interest among many scholars in CSR academia [13]. However, the findings have been inconclusive and mixed, both positive and negative results have been obtained [14]. For example, Franco, Caroli, Cappa and Chiappa's [15] study shows the impact of social performance on financial return is in $U$ shape. They find CSR is cost effective only when the relationships among hotels and stakeholders are close. Another obvious trend shows the extant literature more focuses on financial returns through social contribution to external stakeholders rather than shareholders [16]. Research in catering industry has confirmed that positive CSR activities can increase financial value only through effective communication between companies and their stakeholders, otherwise CSR will not generate financial benefits [14]. Therefore, a critical review is needed for investigating the status quo of the extant literature, research gap and identifying further research directions.

\section{METHODOLOGY}

\subsection{Critical review}

Critical review method is applied in this research which requires "critical thinking and analysis on the part of the reviewer in order to identify, recommend, and conceptualize original thinking and in so doing to make a significant contribution to the body of literature within the review scope" [17]. Thus, the suggestions and ideas generated during the review process ought to "derive from the critical analysis and synthesis of included literature, thus resulting in a synthesis of existing models, theories, or hypotheses" [17]. Several critical reviews and longitudinal studies have been conducted in the CSR related fields. For example, Theodoulidis, Diaz, Crotto and Rancati [18] critically reviewed studies in the relationship between CSR and financial performance. In their research, the correlation as aforementioned was explored from stakeholders' perspective. In this study, relevant literature from 2010 to 2020 in hospitality academia is analysed.

\subsection{Sampling and data collection}

Journal papers related to the observed areas are collected from five creditable and well-known databases namely "ScienceDirect", "Taylor \& Francies Online", "SAGE Journals", "Emerald Insight" and "Scopus". Journal articles published during 2010-2020 are reviewed due to the intensive attention paid on CSR issues by scholars from hospitality field after a major recession in 2007-2008 and European debt crisis in 2009. As mentioned in Forética's [19] research, $84 \%$ of the companies they surveyed pointed out the importance of CSR in the following years. Several key words are used to locate the relevant articles, such as "CSR", "financial performance", "hospitality industry", "sustainability", "social reporting", "hotel operation". Finally, 69 articles are found for further content anlaysis.

\subsection{Content analysis}

In Moyeen, Kamal and Yousuf's [20] research, they find more and more academic publications in CSR adopted content anlayisis which is considered as a valuable method. Both quantitative and qualitative content analysis methods are used in this research. Eight dimensions of the collected papers have been identified for the content analysis including topic, year, scope, methodology, results and findings, contribution, limitation and future research direction. Respective key words are also listed for locating the related sections and content. Parellel coding method has been adopted and the inter-coder reliability reached to $89 \%$ which is within the threshold of $85 \%$ [21].

\section{FINDINGS AND DISCUSSIONS}

\subsection{Findings}

Overall, there is an increasing trend in the quantity of the journal articles during the observed period. The sharp increment during 2019-2020 is mainly due to industry's CSR performance during pandemic period which has drawn much attention from the academia for further investigation. As mentioned in Noronha, Guan and Sio's research, large hotel groups proactively took some CSR activities and make social contribution during the most difficult times of COVID-19 period [22]. The similar 
situation also happened during 2013-2014 which is within the serious financial recession period in many countries around world, such as European sovereign debt crisis, Greek government-debt crisis, Portuguese financial crisis, Russian financial crisis and Brazilian economic crisis.



Figure 1. No. of articles by year

Figure 2 demonstrates a "data map". It is noted majority of the studies were with the research scope based in North America, Europe as well as Asia. More than $40 \%$ of the collected papers are from US, around $15 \%$ are from Spain and $8 \%$ from China.

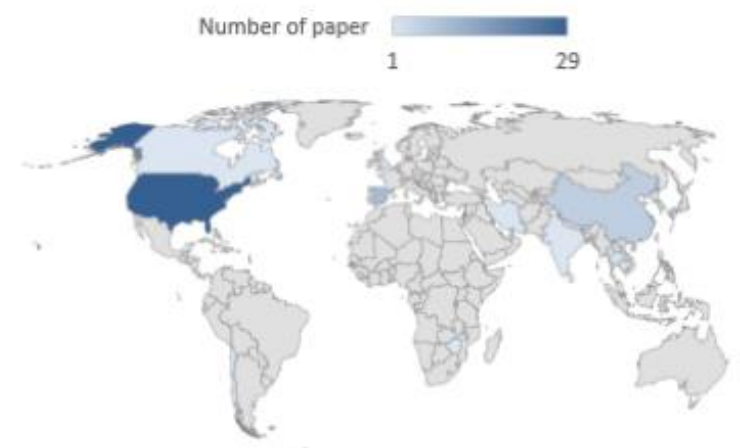

Figure 2. Gegraphic distribution

Regarding the topics, 27 of the collected journal articles are related to "CSR practice in hospitality industry and the relationship between CSR and financial performance". 17 articles are in the topics of "moderating effect between CSR and financial performance. The third top popular topic is "performance evaluation of CSR" which accounts for 9 papers. As shown in the word cloud (see Figure 3) computed based on the keyword frequency of the collected articles, sustainability, stateholder theory, green practice, environmental governance, catering and tourism industries have also attracted much research interests beside the key topics as aforementioned.

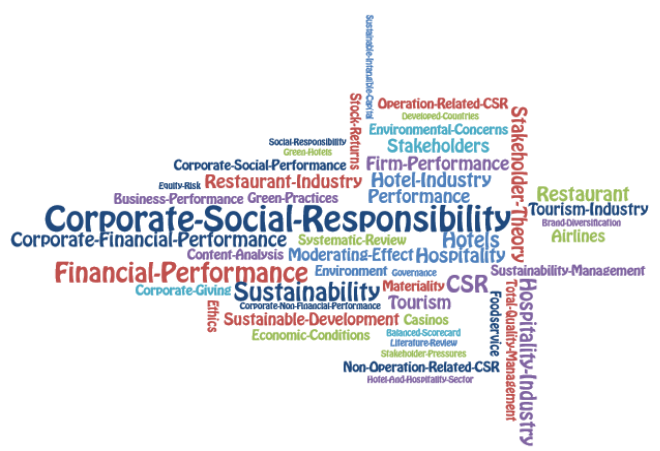

Figure 3. Word cloud of top 50 keywords

As for the research methods, quantitative approach $(71 \%)$ is the major research method applied while quanlitative approach accounts for $28 \%$ (see Figure 4). Mixed research method only occupy $1 \%$ of the samples. Among the collected papers, three of them are in the form of critical review and four of them applied content analysis.

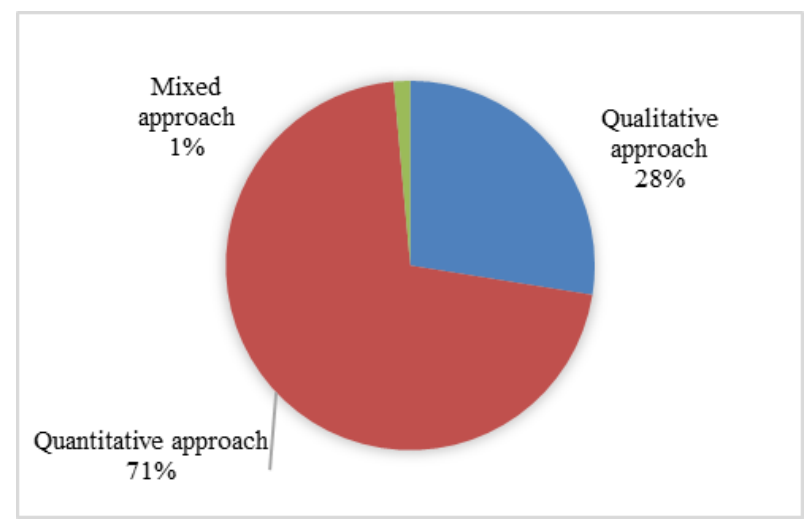

Figure 4. Research methods applied

In regards of the research findings, 37 studies identify positive association between CSR and financial performance in the hospitality industry while ten papers show out negative relationship. Seven papers cannot find any association between these two main variables of interests.

Based on the research results, around one thirds of the studies mention conceptual framework or theoretical model is urgently called for further research. Majority of them also point out the limitation in sample size, cultural bias and difficulty in accessing specific samples.

\subsection{Discussions}

According to the findings, in hospitality academia, scholars prefer to use US data for quantitative analysis. The reason behind is the database in US is more advanced and with certain level of diversity. Qualitative research in this field is more focused on European market with more theoretical frameworks and in-depth qualitative analysis. It is mainly 
due to Europe is considered as a kind of birth place of CSR related theories.

In recent years, stakeholders are regarded as the major driving force for companies to perform CSR. Therefore, the review result also shows during the observed periods, the theoretical basis shifts from legitimacy perspective to stakeholder perspective. The trend is stimulated by the changes of social focus in the hospitality industry.

Mixed results have been identified in the relationship between CSR and financial performance. The negative results are often identified for those companies incurring loss. The reason behind is during the recession or pandemic periods, the primary objective of a company should be "maximizing shareholder's wealth and minimizing potential loss" based on stakeholder theory. However, many hotels keep doing CSR without foreseeable financial return in short-term which is considered as a "regression". If a company fails to fulfill its most basic social responsibility which is to generate profit and sustain its business, it is impossible for this company to secure its other social responsibilities, such as ensuring staff benefit, paying off liabilities, protecting environment, making contribution to the society. In contrast, companies with profitable operations can obtain more appreciation from stakeholders upon the CSR contribution they have made. Therefore, it is suggested public companies need to find ways to keep balance between degree of CSR involvement and their financial performance in order to achieve the sustainable development goals.

\section{CONCLUSION}

In summary, this study has reviewed 69 papers published in well-known and creditable journals related to CSR and financial performance in hospitality industry. The results demonstrate quantitative method is the main stream of methodology used in this academia and US dataset is more preferable. In addition, stakeholder perspective refers to the most popular school of theoretical basis in recent years. Although majority of the studies have proved positive association between CSR and financial performance, negative relationship is still very obvious and sound for loss-making firms. Besides, many studies suggest developing conceptual framework or furthering the extant theoretical framework to cope with the rapid changes in CSR fields as well as diversified CSR behaviour of the public companies in today's business world.

For the research contribution and significance, the findings of this critical review can bring additional insight to the CSR and hospitality academia and can stimulate scholars' further study on how to achieve balance between social and financial performance of companies in this industry. Theoretically, this critical review enlightens the need of developing/extending the classical theoretical model for matching with the new phenomenon in the CSR field. Practically, the review results also can provide valuable information and suggestions to industry operators for their improvement in CSR practice.
Last but not the least, this critical review is limited to one particular industry. For future study, a broader review can be conducted to cover all the main industry streams in the capital market.

\section{REFERENCES}

[1] S.Y. Park, and S.E. Levy, Corporate social responsibility: perspectives of hotel frontline employees, Int. J. Cont. Hospi. Manage., 2014, 26(3), pp.332-348. DOI: 10.1108/IJCHM-01-2013-0034

[2] T. Coles, E. Fenclova, and C. Dinan, Tourism and corporate social responsibility: A critical review and research agenda, Tour. Manage. Persp., 2013, 6, pp.122141. DOI: 10.1016/j.tmp.2013.02.001

[3] E.F. Brigham, and J.F. Houston, Core concepts of financial management, Singapore: Cengage Learning Asia, 2011.

[4] C. Deegan, and C. Blomquist, Stakeholder influence on corporate reporting: an exploration of the interaction between WWF-Australia and the Australian minerals industry, Acc., Org. Soci., 2006, 31(4), pp.343-372. DOI:10.1016/j.aos.2005.04.001

[5] C. Deegan, The legitimising effect of social and environmental disclosures - a theoretical foundation, Acc., Audit. Acc. J., 2002, 15(3), pp.282-311. DOI:10.1108/09513570210435852

[6] C. K. Lindblom, The implications of organizational legitimacy for corporate social performance and disclosure, Conference presentation at the Critical Perspectives on Accounting Conference, New York, NY, 1994.

[7] P. Bansal, and K. Roth, Why companies go green: a model of ecological responsiveness, Aca. Manage. J., 2000, 43(4), pp.717-736. DOI:10.2307/1556363

[8] J.S. Kim, H.J. Song, C.K. Lee, and J.Y. Lee, The impact of four CSR dimensions on a gaming company's image and customers' revisit intentions, Int. J. Hosp.

Manage., 2017, 61, pp.73-81. DOI: 10.1016/j.jhm.2016.11.005

[9] L.D. Parker, Social and environmental accountability research: a view from the commentary box, Acc., Audit. Acc. J., 2005, 18(6), pp.842-860. doi:10.1108/09513570510627739

[10] R.E. Freeman, A.C. Wicks, and B. Parmar, Stakeholder theory and "the corporate objective 
revisited", Org, Sci., 2004, 15(3), pp.364-369. DOI: $10.1287 /$ orsc. 1040.0066

[11] R.E. Freeman, Strategic management: a stakeholder approach, Boston, MA: Pitman, 1984.

[12] A. Farmaki, Corporate social responsibility in hotels: a stakeholder approach, Int. J. Cont. Hospi. Manage., 2018, 31(6), pp.2297-2320.

DOI: 10.1108/IJCHM-03-2018-0199

[13] J.C. Sang, Y.C. Chune, and J. Young, Study on the relationship between CSR and financial performance,

Sustainability, Sustain. J., 2019, 11(2), pp.343.

DOI: $10.3390 /$ su 11020343

[14] Y. Rhou, M. Singal, and Y. Koh, CSR and financial performance: the role of CSR awareness in the restaurant industry, Int. J. Hospi. Manage, 2016, 57, pp.30-39. DOI: 10.1016/j.ijhm.2016.05.007

[15] S. Franco, M.G. Caroli, F. Cappa, and G.D. Chiappa, Are you good enough? CSR, quality management and corporate financial performance in the hospitality industry, Int. J. of Hospi Manage, 2020, 88. DOI: 10.1016/j.ijhm.2019.102395

[16] S. Lee, M. Singal, and K.H. Kang, The corporate social responsibility - financial performance link in the U.S. restaurant industry: do economic conditions matter? Int. J. Hospi. Manage, 2013, 32, pp.2-10. DOI: $10.1016 / j . \mathrm{ijhm} .2012 .03 .007$
[17] W. Klerk, and J. Pretorius, Guideline for conducting critical reviews in psychology research, J. Psy. Africa, 2019, 29(6), pp.645-649.

DOI: $10.1080 / 14330237.2019 .1691793$

[18] B. Theodoulidis, D. Diaz, F. Crotto, and E.

Rancati, Exploring corporate social responsibility and financial performance through stakeholder theory in the tourism industries, Tour. Manage., 2017, 62, pp.173188. DOI: 10.1016/j.tourman.2017.03.018

[19] Forética, Forética report: Evolution of corporate responsibility in companies in Spain, 2011

[20] A. Moyeen, S. Kamal, and M. Yousuf, A content analysis of CSR research in hotel industry, 2006-2017, Responsibility and Governance, 2018, pp.163-179.

DOI: 10.1007/978-981-13-1047-8_10

[21]C. O'Connor, J. Helene, Intercoder reliability in qualitative research: debates and practical guidelines, Int. J. Quali. Meth., 2020,

DOI:10.1177/1609406919899220

[22] C. Noronha, J. Guan, and S. H. I, Sio, Accounting for gaming in the time of plague: COVID-19 in Macau, Sustain. Acc., Manage. Pol. J., 2021, 12(5), pp.943964. DOI: 10.1108/SAMPJ-12-2020-0423. 